\title{
Clinical Significance of ST Segment Elevation in Posterior Leads V7, V8 and V9 in Patients with Acute Inferior Wall Myocardial Infarction
}

\author{
Dipesh Pradhan ${ }^{1}$, Sun Jian ${ }^{1 *}$, Rajina Shrestha ${ }^{2}$, Madhu Gupta ${ }^{1}$, Sanjaya Karki ${ }^{3}$, Liu Xiao Fei ${ }^{1}$ and Dr Shekhar Rajbhandari ${ }^{4}$
}

${ }^{1}$ Department of Internal Medicine (Cardiology), Norman Bethune of College of Medicine, The First Hospital of Jilin University, Changchun 130021, China ${ }^{2}$ Department of Obstetrics and Gynecology, Jiamusi University, China

${ }^{3}$ Department of Emergency Medicine, Norman Bethune of College of Medicine, Jilin University, Changchun 130021, China

${ }^{4}$ Department of Cardiology, Norvic International Hospital, Kathmandu, Nepal

\begin{abstract}
Objectives: The aim of the study was to assess the role of ST segment elevation in the Posterior leads V7, V8, and V9 for the diagnosis of acute posterior wall infarction and the identification of infarct related artery (IRA) in patients with acute inferior wall MI.

Background: The posterior wall infarction is difficult to diagnose through standard 12 lead ECG alone, especially in the acute setting.

Methods: In our retrospective study, 121 patients (101 male, 20 female) with an inferior acute MI, were included They were divided into two groups according to the presence (Group A: mean age $60.00 \pm 10.05$ years) or absence (Group B: mean age $57.65 \pm 12.86$ years) of ST segment elevation in leads V7, V8, V9. Complete demographic data were recorded in all subjects, the infarct size was estimated by CPK MB, left ventricular function was assessed by echocardiographically and infarct related artery patency was evaluated by coronary angiography.
\end{abstract}

Results: Group A patients had a higher frequency of Left cirucumflex occlusion than group B patients $(n=33$, $27.3 \%$ vs. $n=4,3.3 \%, p=0.0001)$. Group $A$ had a more extensive infarction, as is shown by CPK MB values (90.12 \pm 33.42 vs $45 \pm 38.28, P=0.0001$ ) but with no difference in left ventricular ejection fraction.

Conclusion: ST segment elevation in posterior leads helps to diagnose left circumflex artery as a culprit IRA in an acute inferior wall Ml with extensive infarct area involving posterolateral walls.

Keywords: Posterior leads; Infarct related artery; ST elevation myocardial infarction; Left circumflex artery; Right coronary artery

\section{Introduction}

ECG diagnosis of a posterior wall myocardial infarction is difficult to diagnose through the standard 12 lead ECG, especially in the acute stage. The posterior wall MI may occur as an isolated event or often associated with an inferior wall myocardial infarction Posterior leads V7, V8 and V9 are usually ignored but it is suggested that these leads can provide ECG information that is useful for characterization of inferior AMI and diagnosis of posterior wall MI [1,2]. 15 or 18 leads ECG should be performed to correctly diagnose culprit artery in inferior wall MI. ST elevation in inferior and posterior leads (V7, V8 and V9) is usually associated with occlusion of the left circumflex artery with the involvement of large infarct zone and complications $[3,4]$. ECG detection of posterior infarction is associated with concomitant ST depression in leads V1 to V3. However these changes are neither sensitive nor specific [5-7].

The aim of our study was to assess the ST segment elevation in posterior leads V7, V8, V9 for the identification of IRA and the diagnosis of posterior wall MI. We also dealt with relation of ratio of ST elevation in lead II and lead III to assess the culprit IRA for the patient with inferior wall MI.

\section{Methods}

For the retrospective study, we had collected 355 patients having an acute inferior wall $\mathrm{MI}$ admitted in the cardiovascular department of the First Hospital of Jilin University. The patient's data were collected from Januar, 2011 to December, 2011. Only 121 patients (male 102 and female 19) met our inclusion criteria which include chest pain lasting for more than 30 minutes before hospital admission, elevation of creatinine kinase $(\mathrm{CK}-\mathrm{MB})$ greater than twice the upper limit (normal:
$0-3.5 \mathrm{ng} / \mathrm{ml})$ and the ECG shows ST segment $>0.1 \mathrm{mV}(1 \mathrm{~mm})$ in at least 2 of 3 the inferior leads (II, III and aVF). The patients excluded from the study who had previous history of acute myocardial infarction, coronary artery bypass surgery or percutaneous coronary intervention prior to current hospitalization, evidence of recent left bundle branch block or left ventricular hypertrophy in ECG, and significant stenosis in both LCX and RCA or triple vessel disease so that a single infarct related artery could not be defined.

\section{Electrocardiography}

ECG was recorded in all patients at a paper speed of $25 \mathrm{~mm} / \mathrm{s}$ and voltage $10 \mathrm{~mm} / \mathrm{mv}$. For inferior STEMI, the inclusion criteria are ST elevation $>0.1 \mathrm{mV}$ in at least two of three inferior leads (II, III and aVF).

In addition to standard 12 leads, three posterior chest leads V7 to V9 should be recorded for the study. Posterior leads are recorded on the same horizontal plane as lead V6 more specifically, lead V7 on the posterior axillary line, lead V8 on the posterior scapular line

*Corresponding author: Sun Jian MD, Department of Cardiology, Norman Bethune College of Medicine, The First Bethune Hospital of Jilin University, Changchun 130021, PR China, Tel +8613596462752; Fax +8688783492; E-mail: sunjianjlu@outlook.com

Received March 23, 2013; Accepted April 16, 2013; Published April 23, 2013

Citation: Pradhan D, Jian S, Shrestha R, Gupta M, Karki S, et al. (2013) Clinical Significance of ST Segment Elevation in Posterior Leads V7, V8 and V9 in Patients with Acute Inferior Wall Myocardial Infarction. J Cardiovasc Dis Diagn 1: 106. doi:10.4172/2329-9517.1000106

Copyright: @ 2013 Pradhan D, et al. This is an open-access article distributed under the terms of the Creative Commons Attribution License, which permits unrestricted use, distribution, and reproduction in any medium, provided the original author and source are credited. 
Citation: Pradhan D, Jian S, Shrestha R, Gupta M, Karki S, et al. (2013) Clinical Significance of ST Segment Elevation in Posterior Leads V7, V8 and V9 in Patients with Acute Inferior Wall Myocardial Infarction. J Cardiovasc Dis Diagn 1: 106. doi:10.4172/2329-9517.1000106

Page 2 of 5

(in between V7 and V9), and V9 on the left border of the spine. ST segment elevation $>0.05 \mathrm{mV}(0.5 \mathrm{~mm})$ in the posterior chest leads was considered to be significant because of the greater distance separating the posterior chest wall from the heart.

\section{Coronary angiography}

In our study, coronary angiography was performed in all patients. The coronary angiography was compared with ECG findings of inferior and posterior leads. Total occlusion or critical stenosis $>70 \%$ in one of the coronary arteries is considered to be significant coronary lesion. All the patients had undergone PCI following coronary angiography.

\section{Division of patients}

Patients were divided into two groups according to the presence of ST elevation $>0.05 \mathrm{mV}$ on posterior leads V7, V8 and V9 on the admission of ECG. Group A was the patient group having ST elevation in posterior leads whereas Group B was the patient group having no ST elevation in posterior leads.

\section{Data collection tool}

The contents of the intended queries were written sequentially and data were collected and filled in the respected columns.

\section{Statical analysis}

All tests of significance were 2 tailed and $p$ values of $<0.05$ was considered as statistically significant. The statistical analysis will perform using the SPSS, version 9.0 for windows, statistical package.

\section{Results}

A baseline characteristic group of patients was shown in table 1 . The mean age for group A is $60.00 \pm 10.05$ (50 to 70 years), the mean age for group B is $57.65 \pm 12.86$ ( 45 to 70 years). The disease is very common in male than female ( $83.47 \%$ vs. $16.53 \%)$

Clinical, electrocardiographic and echocardiographic features were listed in table 2. The ECG of inferior wall MI and ECG with posterior lead V7-V9 were shown in figures 1-3. Inferior wall MI with ST elevation in lead III $>$ II was frequently associated with group B patients than group A patients $(\mathrm{n}=72,59.5 \%$ vs. $\mathrm{n}=19,15.7 \%, \mathrm{p}=0.0001)$ whereas ST elevation II>III favors group A patients than Group B patients $(\mathrm{n}=22,18.2 \%$ vs. $\mathrm{n}=8,6.6 \%, \mathrm{P}=0.0001)$ as shown in table 2 . Group A patients had significantly larger infarcts compared to group $\mathrm{B}$ patients which is shown by CPK-MB values (90.12 \pm 33.42 vs. $45 \pm$ $38.28, \mathrm{p}=0.001)$. However, there was no difference in ejection fraction between two groups. The patients with inferior wall STEMI had a normal ST segment in leads V1 to V3 which was more frequently seen in group B patients $(\mathrm{n}=74$ [61.2\%] vs. $\mathrm{n}=29$ [24\%], $\mathrm{p}=0.001)$.

Coronary angiography findings are shown in table 3. Out of 121

\begin{tabular}{|c|c|c|c|}
\hline Characteristics, n=121 & Group A, n=41 & Group B, n=80 & P value \\
\hline Age & $60.00 \pm 10.05$ & $57.65 \pm 12.86$ & \\
\hline Sex Male & $36(87.8 \%)$ & $65(81.3 \%)$ & \\
\hline Female & $5(12.2 \%)$ & $15(18.8 \%)$ & \\
\hline Hypertension-64(52.9\%) & $24(19.8 \%)$ & $40(33.10 \%)$ & 0.3 \\
\hline Diabetes- 26(21.5\%) & $11(9.1 \%)$ & $15(12.4 \%)$ & 0.3 \\
\hline Smoking-70(57.9\%) & $21(17.4 \%)$ & $49(40.5 \%)$ & 0.2 \\
\hline Alcohol-29(24\%) & $12(9.9 \%)$ & $74(61.2 \%)$ & 0.3 \\
\hline Dyslipidemia-87(71.9\%) & $30(24.8 \%)$ & $57(47.1 \%)$ & 0.8 \\
\hline
\end{tabular}

$\mathrm{P}<0.05$ is clinically significant.

Table 1: Baseline characteristics.

\begin{tabular}{|c|c|c|c|}
\hline Characteristics, $\mathbf{n = 1 2 1}$ & Group A, $\mathbf{n = 4 0}$ & Group B, n=81 & p value \\
\hline Killip 1-94(77.7\%) & $32(26.4 \%)$ & $62(51.2 \%)$ & 0.9 \\
\hline ST elevation & & & \\
\hline III>II 91(75.2\%) & $19(15.7 \%)$ & $72(59.5 \%)$ & $0.0001^{* * *}$ \\
\hline II>III 30(24.8\%) & $22(18.2 \%)$ & $8(6.6 \%)$ & $0.0001^{\text {** }}$ \\
\hline ST in V1-V3 & & & \\
\hline Normal 103(85.1\%) & $29(24 \%)$ & $74(61.2 \%)$ & $0.001^{\text {** }}$ \\
\hline Ejection Fraction & $54.56 \pm 7.8 \%$ & $55.9 \pm 7.06 \%$ & 0.3 \\
\hline CPK-MB (ng/ml) & $90.12 \pm 33.42$ & $45 \pm 38.28$ & $0.001^{\text {** }}$ \\
\hline
\end{tabular}

$<0.05=$ clinically significant ${ }^{*},<0.005=$ very highly significant ${ }^{* *},<0.0005=$ very very

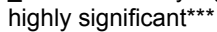

Table 2: Clinical, Biochemical, Electrocardiographic and Echocardiographic characteristics.

patients, $69.42 \%$ has RCA as the culprit artery whereas $30.58 \%$ has LCX occlusion. TIMI O coronary flow was found in 94 patients $(77.4 \%)$. No differences were found between two groups regarding TIMI 0 flow score. The Left Circumflex Coronary Artery (LCX) disease was found significantly higher proportion in group $A(n=33,27.3 \%)$ than in group $\mathrm{B}(\mathrm{n}=4,4.3 \%, \mathrm{p}=0.0001)$ whereas the Right Coronary Artery (RCA) disease was found very frequently in group $B(n=76,62.8 \%)$ than group $A(n=8,6.6 \%, p=0.0001)$.

In our study, $33.88 \%(\mathrm{n}=41)$ patients had ST segment elevation in posterior leads V7-V9 whereas $66.12 \%(\mathrm{n}=80)$ patients had no involvement of posterior wall of the left ventricle. The $>0.1 \mathrm{mv}$ ST elevation in inferior leads II, III and aVF is significant in the diagnosis of inferior wall STEMI. The ratio of ST elevation in leads II and III has clinical implication to predict culprit artery as shown in table 4. In our study, ST elevation in lead III >II was seen in 91 patients $(75.21 \%)$ whereas ST elevation in lead II>III was seen in 30 patients (24.79\%). RCA was very habitually involved in ECG with ST elevation in lead III $>$ II $(n=77,63.6 \%, p=0.0001)$ whereas LCX was the culprit artery in patients having a ST elevation in lead II $>$ III $(n=23,19.3 \%, p=0.0001)$.

\section{Discussion}

The result of our study indicates that ST elevation in the posterior leads V7, V8, V9 is associated with posterolateral wall involvement. In our study, 27.3\% $(n=33)$ group A patients with ST elevation in posterior leads showed left circumflex occlusion compared to $3.3 \%$ $(\mathrm{n}=4)$ group B patients. It suggests that 15 leads ECG provide greater accuracy for the diagnosis of left circumflex occlusion. In general, the 12 lead ECG is less sensitive in identifying left circumflex artery as a culprit IRA. Huey et al. found that $52 \%$ of patients with acute MI from LCX occlusion did not show any ST segment elevation in 12 lead ECG while other investigators suggested that LCX disease either may not cause any ST changes or generate only ST depression in the precordial leads [8-10]. Scintigraphic studies suggested that thallium myocardial perfusion defects in posterolateral segments are highly specific for LCX disease [11]. Hence, posterior leads may help for regional diagnosis of an acute inferior MI.

The posterior leads V7, V8 and V9 has pivotal role in evaluating the pathological processes in the left ventricular posterior myocardial wall. However, they are used undeservingly rarely in a clinical practice [12]. Our first hospital of Jilin University has already makes the guidelines to perfrom posterior and right chest leads (V3R, V4R, V5R) in every patients having ST elevation in inferior leads. The disuse of posterior leads in clinical practice might be due to lack of recent ECG guildelines favouring posterior leads in medical education.

The posterior leads V7-V9 may increase the diagnosis of acute 


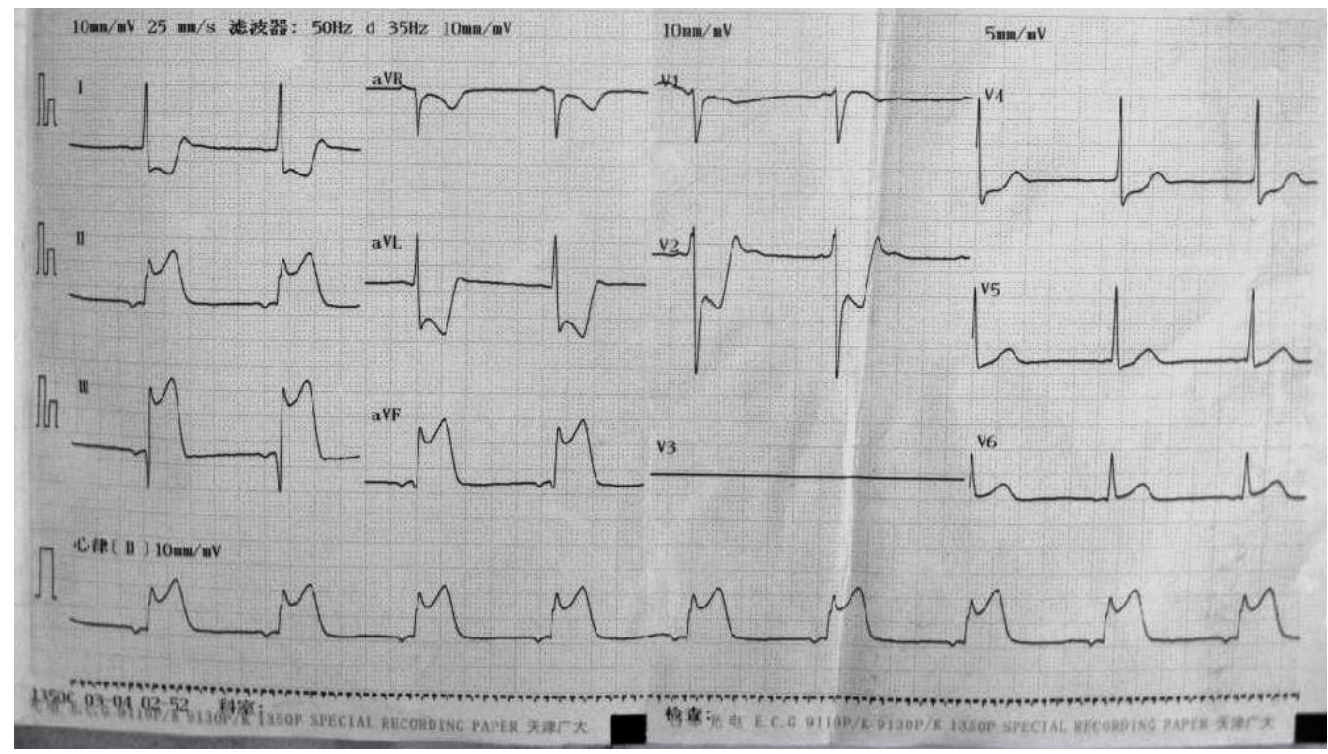

Figure 1: ECG showing ST elevation (III>II) in the inferior leads and ST depression in lead I, aVL, V2 and V4. The posterior leads V7,V8, V9 of this patients was norma which was shown in figure 2 . The coronary angiography later confirmed right coronary artery occlusion.

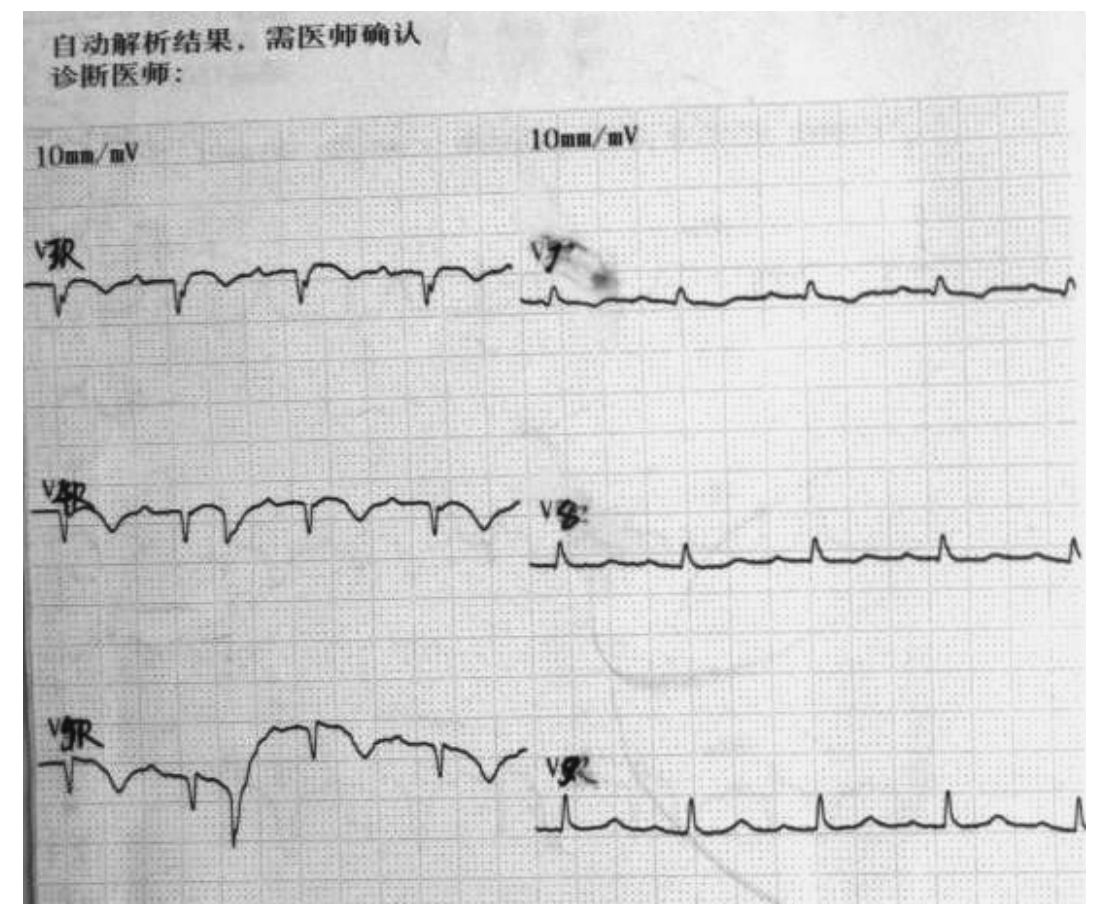

Figure 2: posterior leads V7, V8, V9 with no ST elevation.

MI (30000 patients/year in the USA with ST segment elevation in the posterior leads) when there is LCX occlusion, resulting in a survival benefit of 500 patients/year through reperfusion therapy. The same study suggests that the addition of posterior leads in routine 12 lead ECG increase the sensitivity from $57.7 \%$ to $59.7 \%$ resulting in better clinical outcome $[13,14]$. Wung and Drew found that the ST elevation $>0.5 \mathrm{~mm}$ in the 15 lead ECG including posterior leads can improve the sensitivity the diagnosis of acute coronary syndrome accredited to LCX occlusion by at least $94 \%$ [15]. Schmitt et al. found that the addition of posterior leads V7-V9 to the routine 12 lead ECG in the ED increase the sensitivity of detecting ST elevation from $50 \%$ to $61 \%$ [16]. In our study, the sensitivity and specificity of posterior leads to diagnose LCX occlusion were $84 \%$ and $90 \%(\mathrm{P}=0.0001)$ respectively also suggested the importance of 15 lead ECG to diagnose posterior wall MI in every acute inferior MI. All these studies point towards the low sensitivity of standard 12 ECG leads to the detection of LCX occlusion and recommend posterior leads $\mathrm{V} 7-\mathrm{V} 9$ for the complete diagnosis of inferior wall MI.

Matetzky et al. found that ST segment elevation in posterior leads 


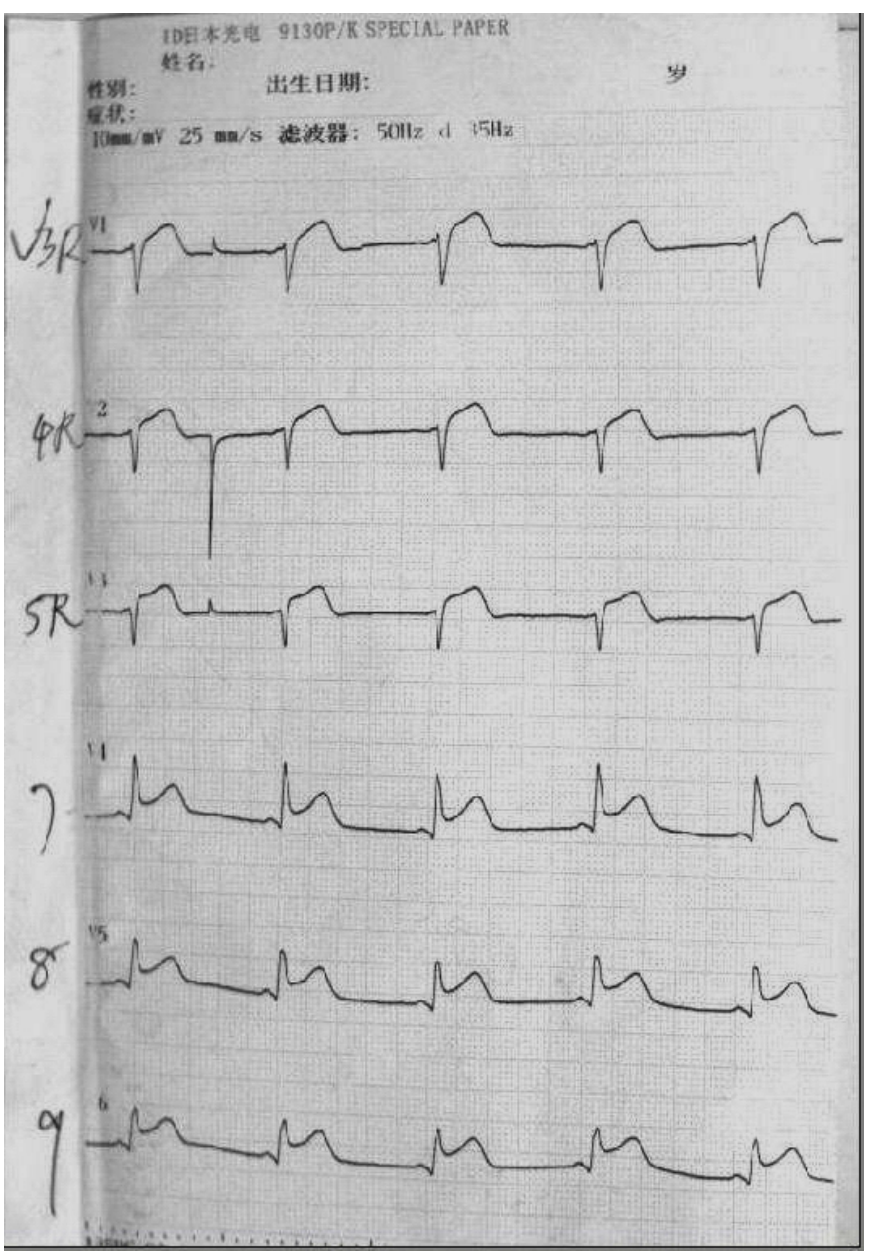

Figure 3: Posterior leads V7, V8, V9 showing ST elevation $>0.05$. There were also ST elevation in right chest leads V3R to V5R. The coronary angiography of this patient showed left circumflex artery occlusion.

\begin{tabular}{|c|c|c|c|}
\hline Characteristics, n=121 & Group A, n=41 & Group B, n=80 & P value \\
\hline TIMI O-94(77.7\%) & $32(26.4 \%)$ & $62(51.2 \%)$ & 0.9 \\
\hline LCX 37(30.6\%) & $33(27.3 \%)$ & $4(3.3 \%)$ & $0.0001^{\text {*** }}$ \\
\hline RCA 84(69.4\%) & $8(6.6 \%)$ & $76(62.8 \%)$ & $0.0001^{\text {*** }}$ \\
\hline
\end{tabular}

LCX=Left Circumflex Artery, RCA=Right Coronary Artery

Table 3: Coronary angiography findings.

\begin{tabular}{|c|c|c|c|}
\hline Characteristics, $\mathbf{n = 1 2 1}$ & RCA & LCX & P value \\
\hline ST Elevation & & & \\
\hline III>II $91(75.21 \%)$ & $77(63.6 \%)$ & $14(11.6 \%)$ & $0.0001^{\text {***}}$ \\
\hline II>III 30(24.79\%) & $7(5.8 \%)$ & $23(19.3 \%)$ & $0.0001^{\text {***}}$ \\
\hline
\end{tabular}

Table 4: Clinical significance of ST elevation in the inferior leads (II, III and aVF) to predict culprit artery either RCA or LCX.

has larger area of infarction as estimated by high CPK MB levels, and higher incidence of complications like reinfarction, post infarction angina, heart failure and death [13]. In our study, group A patients had large infarct area with high CPK MB $(90.12 \pm 33.42$ vs. $45 \pm 38.28$, $\mathrm{P}=0.0001$ ) than group $\mathrm{B}$ patients but there was no significant change in ejection fraction between two groups.

The ECG findings of ST elevation in posterior lead provide greater accuracy for the diagnosis of posteroinferior MI than the associated
ST depression in precoardial leads. ST depression in anterior leads is not specific and may also reflect anterior wall ischemia or non Q wave MI. Precordial ST Segment may be diminished by right ventricular infarction or may be masked by the development of complete right bundle branch block pattern [17]. Consequently, this ECG sign is of low sensitivity and specificity for the diagnosis of posterior wall infarction [18]. The ECG of the posterobasal myocardial infarction shows incrased R wave amplitude in leads V1-V3. The abnormal Q wave is not seen in the regular 12 leads ECG. However, Q wave can appear in the posterior leads V7, V8 and V9 during ECG registration [19]. In our study, normal ST segment in V1-V3 was frequently seen in group B than Group A patients $(\mathrm{n}=74$ [61.2\%] vs. $\mathrm{n}=29$ [24\%], $\mathrm{p}=0.0001$ ). It further justifies that ST segment is normal in the anterior precordial leads in case of posterolateral MI.

Tierala et al. proposed that RCA might be the culprit IRA if the ST elevation lead III>II whereas the LCX might the culprit coronary artery if ST elevation lead II $>$ III in inferior wall MI [20]. In our study, the sensitivity and specificity of ST elevation III $>$ II for RCA are $90 \%$ and $61 \%$ respectively $(\mathrm{P}=0.0001)$ whereas the sensitivity and specificity of ST elevation II $>$ III for LCX are $61 \%$ and $90 \%$ respectively. Interestingly, ST elevation II $>$ III frequently favored ST elevation in posterior leads as seen in group A compared to group B patients $(\mathrm{n}=22,18.2 \% v s . \mathrm{n}=8$, $6.6 \%, \mathrm{P}=0.0001)$ whereas the ST elevation III $>$ II recurrently favored group $\mathrm{B}$ compared to group $\mathrm{A}(\mathrm{n}=72,59.5 \%$ vs. $\mathrm{n}=19,15.7 \%, \mathrm{P}=0.0001)$.

The present study was limited by its rather small sample size. The study did not deal in predicting the lesion either proximal or distal coronary occlusion. Although the right chest leads V3R, V4R, V5R has pivotal role to know the pathological process of inferior wall MI, they are not taken for study and comparison. The study lacked the follow up and complications like reinfarction, post infarction angina, arrhythmias and mortality.

\section{Conclusion}

We recommend routine recording of posterior leads V7, V8 and V9 in all patients admitted to the hospital with an acute inferior wall MI. ST elevation in the posterior leads in inferior wall MI are frequently implicated with the lesion in the left circumflex artery. The posterior wall MI are associated with large area of jeopardized myocardium, might argue in favor of reperfusion therapy.

\section{References}

1. Trzeciak S, Erickson T, Bunney EB, Sloan EP (2002) Variation in patient management based on ECG interpretation by emergency medicine and internal medicine residents. Am J Emerg Med 20: 188-195

2. Hathaway WR, Peterson ED, Wagner GS, Granger CB, Zabel KM, et al. (1998) Prognostic significance of the initial electrocardiogram in patients with acute myocardial infarction. GUSTO-I Investigators. Global utilization of streptokinase and t-PA for occluded coronary arteries. JAMA 279: 387-391.

3. Birnbaum, Y and B Drew (2003) The electrocardiogram in ST elevation acute myocardial infarction: correlation with coronary anatomy and prognosis. Postgrad Med J 79: 490-504.

4. Menown IB, Allen J, Anderson JM, Adgey AA (2000) Early diagnosis of right ventricular or posteriinfarction associated with inferior wall left ventricular acute myocardial infarction. Am J Cardiol 85: 934-938.

5. Gibson CM, Chen M, Angeja BG, Murphy SA, Marble SJ, et al. (2002) Precordia ST-segment depression in inferior myocardial infarction is associated with slow flow in the non-culprit left anterior descending artery. J Thromb Thrombolysis 13: 9-12.

6. Birnbaum Y, Wagner GS, Barbash GI, Gates K, Criger DA, et al. (1999) Correlation of angiographic findings and right (V1 to V3) versus left (V4 to V6) precordial ST-segment depression in inferior wall acute myocardial infarction. Am J Cardiol 83: 143-148. 
Citation: Pradhan D, Jian S, Shrestha R, Gupta M, Karki S, et al. (2013) Clinical Significance of ST Segment Elevation in Posterior Leads V7, V8 and V9 in Patients with Acute Inferior Wall Myocardial Infarction. J Cardiovasc Dis Diagn 1: 106. doi:10.4172/2329-9517.1000106

Page 5 of 5

7. Porter A, Vaturi M, Adler Y, Sclarovsky S, Strasberg B, et al. (1998) Are there differences among patients with inferior acute myocardial infarction with ST depression in leads V2 and V3 and positive versus negative T waves in these leads on admission? Cardiology 90: 295-298.

8. Huey BL, Beller GA, Kaiser DL, Gibson RS (1988) A comprehensive analysis of myocardial infarction due to left circumflex artery occlusion: comparison with infarction due to right coronary artery and left anterior descending artery occlusion. J Am Coll Cardiol 12: 1156-1166.

9. Agarwal JB, Khaw K, Aurignac F, LoCurto A (1999) Importance of posterior chest leads in patients with suspected myocardial infarction, but nondiagnostic, routine 12-lead electrocardiogram. Am J Cardiol 83: 323-326.

10. Jacobs AK, French JK, Col J, Sleeper LA, Slater JN, Carnendran L, et al. (2000) Cardiogenic shock with non-ST-segment elevation myocardial infarction: a report from the SHOCK Trial Registry. SHould we emergently revascularize Occluded coronaries for Cardiogenic shocK? J Am Coll Cardiol 36: 1091-1096.

11. Newman HN, Dunn RF, Harris PJ, Bautovich GJ, McLaughlin AF, et al. (1983) Differentiation between right and circumflex coronary artery disease on thallium myocardial perfusion scanning. Am J Cardiol 51: 1052-1056.

12. http://medspecial.ru/wiki

13. Matetzky S, Freimark D, Feinberg MS, Novikov I, Rath S, et al. (1999) Acute myocardial infarction with isolated ST-segment elevation in posterior chest leads V7-9: "hidden" ST-segment elevations revealing acute posterior infarction. J Am Coll Cardiol 34: 748-753.

14. Zalenski RJ, Rydman RJ, Sloan EP, Hahn KH, Cooke D, et al. (1997) Value of posterior and right ventricular leads in comparison to the standard 12-lead electrocardiogram in evaluation of ST-segment elevation in suspected acute myocardial infarction. Am J Cardiol 79: 1579-1585.

15. Wung SF, Drew B (1999) Comparison of 18-lead ECG and selected body surface potential mapping leads in determining maximally deviated ST lead and efficacy in detecting acute myocardial ischemia during coronary occlusion. J Electrocardiol 32: 30-37.

16. Schmitt C, Lehmann G, Schmieder S, Karch M, Neumann FJ, et al. (2001) Diagnosis of acute myocardial infarction in angiographically documented occluded infarct vessel : limitations of ST-segment elevation in standard and extended ECG leads. Chest 120: 1540-1546.

17. Drew BJ, Adams MG, Pelter MM, Wung SF, Caldwell MA (1997) Comparison of standard and derived 12-lead electrocardiograms for diagnosis of coronary angioplasty-induced myocardial ischemia. Am J Cardiol 79: 639-644.

18. Assali AR, Herz I, Vaturi M, Adler Y, Solodky A, et al. (1999) Electrocardiographic criteria for predicting the culprit artery in inferior wall acute myocardial infarction. Am J Cardiol 84: 87-899, A8.

19. http://www.medkurs.ru/kardiolog/karddiag/diagnostisszab/23140.html

20. Tierala I, Nikus KC, Sclarovsky S, Syvänne M, Eskola M, et al. (2009) Predicting the culprit artery in acute ST-elevation myocardial infarction and introducing a new algorithm to predict infarct-related artery in inferior ST-elevation myocardial infarction: correlation with coronary anatomy in the HAAMU Trial. $J$ Electrocardiol 42: 120-127. 